\title{
Inclusion of Young Children with Special Needs in Early Childhood Education in the United States: Advantages and Disadvantages
}

\author{
Siyu Chen ${ }^{1, a, \dagger}$, Qixuan Huang ${ }^{2, b,{ }^{*}, \dagger}$, Zhiyi Liu ${ }^{3, c, \dagger}$, Haijing Wang ${ }^{4, d, \dagger}$ \\ ${ }^{1}$ Tianjin Normal University, Tianjin, Tianjin, China \\ ${ }^{2}$ The George Washington University, Washington DC, District of Columbia, the United States \\ ${ }^{3}$ South China University of Technology, Guangzhou, Guangdong, China \\ ${ }^{4}$ Hangzhou Foreign Language School Cambridge A-Level Center, Hangzhou, Zhejiang, China \\ *Corresponding author. Email:aeiffelhaha@126.com, ${ }^{b}$ schen40@gwmail.gwu.edu, challieme@163.com, \\ dzhiyiliu1234@163.com \\ Those authors contributed equally.
}

\begin{abstract}
As the significance of inclusion prevalently predominate in recent years, educators and professionals draw their attention to inclusion of students in educational settings in America. Including students with learning disabilities in general educational setting is a relatively debatable topic in the American society. The main goal of this article is to explore the importance of inclusive education for both ordinary and special needs students. It aims to use critical discourse analysis to examine how effectively inclusion is represented among American children in their early years. It also reveals advantages and disadvantages of the inclusive system in various aspects. Reviewing past literature, we find out that inclusion provides equal chances for all students, achieves interdependence among ordinary and special needs students, aid special needs students in adapting to society easier, and demonstrates diversity in teaching methods. However, we also discover that inclusion tends to cause problems like peer reject, curricular inflexibility, immaturity in system construction, as well as deadlock among teachers. At the end of this article, we provide relatively feasible recommendations for further improvements in the practices of inclusive system in education.
\end{abstract}

Keywords: Inclusion, Primary education, Advantages, Disadvantages, Recommendations.

\section{INTRODUCTION}

National Center in Educational Restructuring and Inclusion (NCERI) defined inclusion as "providing to all students, including those with severe disabilities, equitable opportunities to receive effective educational services, with supplementary aids and support services as needed, in age-appropriate general education classes in their neighbourhood schools, toward the outcome of preparing all students for productive lives as full members of the society" [1]. Inclusive education is one of the important trends in the progress of special education in the world at present. Among them, inclusive education in the United States is at the forefront of this change. In November 1975, The Education for All Handicapped Children Act (EAHCA) required schools to provide free appropriate public education (FAPE) and guaranteed students with
Individualized Education Programs (IEPs) to participate in the least restrictive environment (LRE). After decades of development, inclusive education for preschool students in the United States has formed a relatively complete system. It is becoming increasing common to include children with special needs in general education classrooms [2,3]. They actively attend academic contests and extracurricular activities of school community and achieve success under intensive instructions and behavioural guidance [4]. According to data from the 2017 2018 school year, about 14\% of school-age children in the United States were enrolled in the special education system. Among them, more than $90 \%$ of special children attend regular public schools, and more than $60 \%$ of special children spend at least $80 \%$ of their daily school hours in ordinary classes. 
According to several studies, including students with learning disabilities in normal educational settings is beneficial from four distinct perspectives:

a) Equitable opportunities for all students: some scholars indicated that inclusion demonstrates an idea of treating every student equally. In other words, perceive difference in students with disability as ordinary instead of bizarre [5-6]. due student no matter they are disabled in any kind or healthy equal chances to learn.

b) Interdependence: inclusion leads to interdependence, which reciprocally strengthens the foundation of inclusion in education. Due to inclusion, students with disabilities mutually coexist with others in the same environment, which not only improves disabled students' social skills, but also facilitates learning in mentally healthy children. Also, interdependence establishes more stable basis for the application of inclusion in education because students from general classroom could find out the merits of students with learning disabilities, to further respect them instead of discriminating against [5-8].

c) Easier social adaption: general educational setting is a reflection of the society and getting familiar with the social system earlier helps students with learning disabilities adapt to normal life in society quicker and better [9]. Because it is not realistic to exclude population with disabilities out of the society, and disabled people cannot live without supports from others, fortunately, inclusion is a panacea fixing this problem.

d) Diversity in teaching methods: inclusion not only increases the quality of educators by making teachers work as a team to learn from diverse specializations, but also ensures the high quality of instruction by revising the system to be more inclusive and comprehensive [1012].

However, it is argued by other researchers that inclusive programming often seems to exert some problems:

a) One main problem shows the difficulty in involving normal students and special need students in an inclusive environment. It is strongly discussed whether special students are truly welcomed by classroom community is determined from several aspects [13-15]. It is also under discussion that whether students with learning disabilities in inclusive lessons are likely to stay consistent with their disable labels [16].

b) Besides, there are also some researchers arguing that inclusive education is overloaded for both special and normal students. Since inclusive classes are acting as the combination of general lessons and special lessons, they require students with learning disabilities to put more efforts compared to classic special schools, which may result in overloaded study pressure. There is also possibility that inclusive classrooms may have negative effects on normal students, making the education of special students more controversial $[17,18]$.

c) Furthermore, current studies have shown that the educational system of inclusion is not mature. James and Nancy L [19] have stated in their paper that most instructions are a waste of time as resources fail to deliver high-quality instruction. The reason for this situation is due to several factors such as little coordination with general education, limited instructional time and unclear accountability [20-24]. It is also reported that teachers fail to educate special students in inclusive classrooms in an appropriate way [25-27].

d) What's worse, there is enough evidence demonstrating that the immature inclusion has put teachers under extreme pressure, leading to their unwillingness of participating in inclusive teaching. Teachers found it difficult to provide appropriate instructions for special students in general classrooms and felt unprepared for the heavy workload [25]. Therefore, caseloads have increased in recent decades [28-31].

To sum up, because of shortcomings mentioned above, the application of inclusion to general classrooms is still under heated discussion.

The key purpose of this paper is to discuss the value of the inclusive education for both typical children and those with special needs by the means of reviewing and assessing its positive and negative effects. Meanwhile, the focus within this paper also lies on some recommendations for improving inclusion classrooms in the United States generally. This paper is structured as follows: We will firstly examine the advantages of inclusive education for youngsters in the United States. In general, a larger proportion of researchers sides with the idea of inclusion in terms of social justice and equal rights, interdependence, social adaption capability as well as diversity in teaching methods. The next section refers to the negative influences that the inclusion exerts. These issues mainly focus on peer rejection, rigid curricula, underdeveloped inclusive system and deadlock among teachers. The remaining parts focus on some proposals for strengthening inclusion classrooms in general in the United States. Finally, the conclusion gives a brief summary of the findings and points out the limitations and suggestions for further research as well.

\section{ADVANTAGES ON INCLUSION}

\subsection{Equitable Opportunities for All Students}

From equal rights and social justice perspective, a huge body of literature argues that inclusion can provide 
equitable opportunities to all students. It is strongly claimed by Anderson that the negative attitudes about impairments and handicapped people must be eradicated in an inclusive community, whether they are the product of stereotypes, prejudice, or unintentional consequences of special education methods [5]. Also, Mittler agrees: 'Inclusion... is about changing schools to make them more responsive to the needs of all children. It is about helping all teachers to accept responsibility for the learning of all children in their school and preparing them to teach children who are currently excluded from their school, for whatever reason [32]'.

Hines and DeYoung yet describe that the human inclination to divide people into categories is a way of ghettoizing, which reveals a socially constructed stigma assigned to individuals who differ from those holding positions of power [7]. When it comes to our topic, the construction of infrastructure and systems aimed towards special needs is how society views, and hence treats handicapped individuals unequally to some extent, though portrayed as a humanitarian gesture designed to assist and protect them. In this instance, inclusive education is advantageous in order to render increasing possibilities for special needs students in terms of equal resources as regular students. The above claims, along with many others, firmly promote the idea that inclusion can present all students with equal chances.

\subsection{Interdependence}

Interdependence refers to two parts in one system coexist and rely on each other to make in-depth progress to benefit the entire system. Interdependence arises from inclusion as equity is encouraged. We are all interdependent upon one another so that what we do affects the lives of others and the earth itself' [33], the world is the world it is right now is because people from distinctive backgrounds coexist and mutually make efforts for human prosperity.

In education, students depend on one another to learn more than an individual student could. In past decades, people have been made enormous efforts to accomplish equity in gender, race as well as culture, as one essential factor in human development, equality in education demands attention as well. People tend to focus on negatives first since they want to remove potential side effects [5]. However, like a coin has two sides, we could not judge others simply based on firstimpression or schemas. Moreover, there are merits students could learn from special students. For example, students with autism spectrum disorder could be talented in arts due to salience effects, which not only attracts other students to communicate with the special student, but also help to gain confidence. Inclusion refers to an environment where everyone gets benefits and is accepted [5]. Statistics stress that people hold an optimistic attitude to welcome special students in general classroom [7], which strengthens the statement that inclusion is the best way to create the environment for students to collaborate with each other as well as truly learn the essence of coexistence and interdependence. In summary, the relationship between interdependence and inclusion is reciprocal that interdependence derives from inclusion as the practice of inclusion in education is encouraged. And interdependence promotes inclusion so that students are more likely to be unified as one group without biases.

\subsection{Easier Social Adaption}

Stepping into a real society, namely an environment without protection of instructors and peers, maybe the most challenging stage for many special needs children. When being included in regular classrooms at young age, students with identified disabilities typically have many non-disabled peer-tutors and role models to help with learning academic subjects and social skills [9]. Such interactions in inclusive classrooms may further facilitate greater understanding and goodwill, which can benefit children who are classified as handicapped in the long run, i.e., appropriate curricular and extra help from teachers and aides, can make it easier for children with disabilities to adapt to the "real world." Moreover, Walther-Thomas and others conducted research showing that students with disabilities developed better self-images, became less critical and more motivated, and recognized their own academic and social strengths. Their social skills improved and positive peer relationships developed [34].

On the contrary, however, in the case that children are classified mentally retarded and placed in special education programs, Mercer noticed that they tend to respond in ways that are consistent with the diagnosis. These same kids performed strikingly like their "normal" peers at home and in other non-school settings. Mercer called these " 6 -hour retarded children" - children who are retarded for six hours a day, that is, when they are in special education [16]. It is worth noting that inclusion renders a re-envisioning of all persons, including those with disabilities. Inclusive societies should be defined by the acceptance that disparities in ability are natural, as well as the promotion of each individual's skills and talents, even those with seriously debilitating conditions or disruptive behaviours. The above analysis has shown that inclusive education is conducive for children with disabilities to adapting to the normal society.

\subsection{Diversity in Teaching Methods}

Diversity is often associated with the idea of inclusive and comprehensive. Hence, diversity in teaching methods refer to more inclusive, comprehensive, and flexible instructions teachers apply 
in classroom to satisfy individual each student's needs. Also, to avoid the concern in the quality of educators in inclusive classroom, it is necessary to facilitate the diversity in teaching methods to assure the stability and fixed quality of instruction.

The reason why diversity in teaching methods exist is that we believe cross-profession teachers exchange ideas on instruction is beneficial for the application of inclusion in education. Teachers with diverse academic backgrounds work together to make efforts to teach them in a more acceptable and comprehensible way. For example, "Universal design for learning" (UDL) is come up when teachers from both general and special needs education cooperate with one another. UDL contains the essence of ideas that a group of teachers conversed, debated, and improved to reduce potential obstacles in courses and instructions for students, including students with learning disabilities [12]. Because of this, students are able to learn quicker, greater and better. More importantly, teachers with distinctive specializations observe the course material from multiple angles, which drives the instructions out of the context so that the main theme becomes more mature and diverse for further applications. In short, on the one hand, educators learn from each other so that the quality of educator is facilitated; on the other hand, diversity in teaching strategies pushes the quality of instructions to a higher level, that is more inclusive and comprehensive (including special education).

\section{DISADVANTAGES ON INCLUSION}

\subsection{Peer Rejection}

Peer rejection involves many behaviours that children use to exclude and hurt each other, including obvious forms of control and exclusion, as well as more subtle strategies such as gossip and spreading rumours. It is known that students' attitudes are influenced by gender; girls tend to hold more positive attitudes than boys toward students with different disability types [35, 36]. Moreover, attitudes are influenced by the type of disability [35, 37]. It has been argued that students' attitudes are least positive toward peers with behavioural problems, such as ADHD and ASD [38]. In the educational context, it has been found that students with behavioural challenges are more difficult to fit in the normal teaching setting than those with other disability types [39]. Their behaviour is often unacceptable by teachers and peers, leading to an increased risk for bullying and social exclusion in class. Students who are not accepted by their peers carry the scars from this not just during school years but throughout their entire life. Although exclusion may not always be intended to cause psychological harm, experiences of exclusion can have detrimental outcomes in terms of emotional and behavioural health, academic difficulties [40], a decrease in prosocial behaviour [41], and low self-esteem $[42,43]$. Therefore, peer rejection has greater impact on school-age children especially children with learning difficulties. To diminish students' negative attitudes, teachers should create a positive learning environment for students to interact with their peers with disabilities. Teachers should creatively encourage the interaction between students, for example, through different forms of classroom seating arrangements to reduce the physical distance between students [44].

\subsection{Inflexible Curriculum}

The current curricula adopted in mainstream schools are not designed based on flexibility and appear to be heavy in content. Within the learning process there are considerable differences among students in relation to the rhythm, deep structure of acknowledgment and the style in which the knowledge was assessed. As a large number of students included in one class, teachers do not have enough time to cater for the wide range of different needs of all learners in the classroom. As a result, young children with special needs experience overloaded learning pressure by attending both general classes and special program. The equality of chances to education means to recognize and respect the differences concerning the capacity and the potential of learning of students. Vast majority of teachers believed that a flexible curriculum provided all children with an opportunity to study and benefit from education. Teachers need to understand that considerable modification of the existing curriculum in regular schools is needed to achieve successful inclusion. Stofile [45] proposed that the curriculum needs to be easily accessible and responsive to the demands of all learners in order to enable schools to adapt diversity in the learner population. Hence, teachers should be allowed to teach at the learners' pace of learning and arrange reasonable teaching content.

\subsection{Immature Inclusive System}

Lots of practices have shown that the current inclusive system is immature. The immaturity of inclusive education makes it less effective in classrooms as experts have expected. For instance, Allington and McGill-Franzen [20,21] examined students' reading progress in special education resource program. Their conclusion shows that there are several reasons for the low efficiency of inclusion. To begin with, most of the inclusive instructions are found to be undifferentiated and thus are not helpful to students with special needs. There is also another study demonstrating that although the concept of inclusion has been brought up in reading education, much time is still spent on independent work, causing reading instruction in these settings to be disjointed and inconsistent to special children [30]. 
Besides, inclusion has little coordination with general education. It seems that inclusive instructions have poor connections with regular lessons, which leads to fragmented learning experiences and lower motivation level among students. What's more, inclusive classes have the tendency of replacing rather than enriching instructions of general teaching, which means that children may miss instructions in general education when they are in inclusive classes. In addition, the responsibility of educating special students is unclear among teachers. There is a possibility that when general teachers and special teachers are both included in the class, the professional accountability for teaching children tends to decrease. Therefore, it is clarified that inclusive has failed to provide special students with instructions in good quality because of its immature class arrangements and responsibility distributions.

\subsection{Deadlock among Teachers}

The immature system of inclusion results in unsatisfactory performance and overwhelming pressure of educators. It is teachers' universal worry that they do not have enough skills to deliver specialize education for students with learning disabilities [26]. In fact, their worry does get confirmed by researches. Due to the difficulty of providing focused, intensive instructions for students with special needs, teachers are more likely to take routine adaptions such as reducing homework and expectations rather than applying specialized instructions [28,46]. Despite of the general worry towards inclusion quality, there are also some worries. For example, some teachers expressed concerns about whether the size of class and grading system should be changed, it is also under heated discussion about how to balance teachers' attention to normal students and special students so that normal students won't feel neglected [47]. Faced to all those worries, additional work load is added to teachers as they are unprepared for inclusive education [48]. As the concept of inclusion is widely used, studies show that caseloads have increased in recent decades [29-31]. What's worse, researches demonstrate that burdens of teaching students in inclusive classrooms make teachers become less positive about their work [49]. In summary, imperfect inclusive systems make educators show limited performance in inclusive instructions and pessimism towards inclusive education.

\section{RECOMMENDATIONS}

Based on the mentioned literatures, we draw the following recommendations:

a) Render pre-inclusion information to all children and their families online or in written paper, including successful cases related to inclusive education and suggestions from educators. b) Aiming at student with learning disability, educators in elementary school should collaborate with the committee to provide a list of teaching strategies for the student with learning disability. The teaching strategies should meet the needs of general courses and special classes, and the individual should take at least three classes in general classroom setting. The amount of class is adjustable depending on the severity of learning disability.

c) Focusing on the students without learning disabilities, educators should be open to any concerns regarding the inclusion of special students. In addition, a paper survey is mandatory to be conducted every Friday, and after completing the survey, students will be appreciated and are able to receive a star representing kindness to others. Also, students are welcome to discuss any concerns with school counsellors who should be specialized in special need education.

d) Introducing new special activities for children with visual and physical disabilities in order to support the specific language such as Braille alphabet, signs language, socializing and community integration activities, practical activities that the student can achieve to prepare himself professionally adjusted to this disability type.

e) Teachers should be trained for inclusive education. Since teachers are lacking skills to educate special students, it is such a necessity for them to receive proper training. Hence, in some certain areas such as Hong Kong, teacher's before-career training has already proven to be effective in improving inclusion's quality and reducing teachers' teaching stress.

f) Use direct and open communication with all students in the inclusive class on why some kids require special support. When instructional or curricular changes are made for certain students but not for others, the same communication should take place.

g) Develop a series of systematic inclusive principles. As inclusive education appears to be ineffective under the circumstance of immaturity, new principles should be imposed by the authorities. For instance, how intensive an inclusive class should be is a problem that needs to be put under discussion.

h) People involved in the students' learning environment, particularly the educators, school administrators and parents, should coordinate with one another towards their children's better development. The final decision whether or not to place special needs students in mainstream schools must be made after careful consideration of all concerned participants as well as the society. 


\section{CONCLUSION}

Based on the discussion of pros and cons about inclusion of young children with special needs in preschool education, inclusion appears to be an educational system worth striving for after considering the positive impacts. The benefits of inclusion consist of promotion of equity and equality for all students, formation of a good environment for both normal students and students with special needs benefiting from their interconnection with each other, the development of greater social skills in students with disabilities, and a better integration of students to society. Moreover, it provides valuable opportunities for teachers to accept individual differences and learn new teaching methods to help the learning process of children with learning difficulties. With regard to the opposite side, it can be divided into four aspects. Firstly, students with special needs suffer from peer rejection in inclusive classrooms, which is detrimental to their social behaviour as well as self-esteem. Secondly, inclusive curriculum exhibits insufficient flexibility, causing students to emerge overwhelmed feelings. Thirdly, inclusive education appears to be immature not only in its teaching methods, but also in its poor distribution of responsibility among educators. Finally, immature inclusive system results in high level of pressure and passive attitudes among teachers, which is adverse in the long term of education. Faced with both sides, this essay has come up with several suggestions ranging from students to teachers. Both normal and special students should receive equal attention and new activities should be applied to the inclusive classrooms. What's more, educators should be trained properly in order to perform better in inclusive classrooms.

As all studies have mentioned above, there is no doubt that the application of inclusive education is crucial to the modern society. With the development of people's material life and the awakening of humanitarianism, inclusive education is what everyone has been asking for. Although current inclusion owns its drawbacks in several aspects, the authors believe that by digging out its errors and marking corrections, a brighter future to an advanced inclusive classroom is on the way.

This paper owns its academic value by discussing merits and demerits of inclusive education. Facing increasingly supported voices of giving equal opportunities to each student, it is crucial for educators to have clear understandings of inclusion and come up with a well-planned strategy. This paper gives educators a succinct analysis of inclusion as well as some fundamental suggestions, helping them conduct in-depth inclusive application in the long term.

\section{REFERENCES}

[1] National Centre on Educational Restructuring and Inclusion. National Study of Inclusive Education; The City University of New York: New York, NY, USA, 1995.

[2] M. Ainscow, \& M. Cesar, (2006). Inclusive education ten years after Salamanca: Setting the agenda. European Journal of Psychology for Education, 21, 231-238.

[3] B.G. Cook, Cameron, D. L., \& M. Tankersley (2007). Inclusive teachers' attitudinal ratings of their students with disabilities. The Journal of Special Education, 40, 230-238.

[4] J. McLeskey, M.S. Rosenberg \& D.L. Westling, (2009). Inclusion: Effective practice for all students. Upper Saddle River, NJ: Pearson Education, Inc.

[5] D.W. Anderson. (2006). Inclusion and interdependence: Students with special needs in the regular classroom. Journal of education and Christian belief, 10(1), 43-59.

[6] N. P. Zigmond. \& A., Kloo. (2017). General and special education are (and should be) different. In Handbook of special education (pp. 249-261). Routledge.

[7] S. G. Hines. \& C. P., Deyoung. Beyond Rhetoic: Reconcilliation as a Way of Life (Valley Forge, PA: Judson Press, 2000)

[8] L. Idol (2006). Toward inclusion of special education students in general education: A program evaluation of eight schools. Remedial and Special education, 27(2), 77-94.

[9] S. Rice. (2003). Response: How Special is Too Special for Inclusion in the Regular Classroom?. Philosophy of Education Archive, 458-461.

[10] J. McLeskey, \& N. L., Waldron. (2011). Educational programs for elementary students with learning disabilities: Can they be both effective and inclusive? Learning Disabilities Research \& Practice, 26(1), 48-57.

[11] M. A. Da Fonte. \& S. M., Barton-Arwood. (2017). Collaboration of general and special education teachers: Perspectives and strategies. Intervention in School and Clinic, 53(2), 99-106.

[12] M. Cochran-Smith. \& C., Dudley-Marling. (2012). Diversity in teacher education and special education: The issues that divide. Journal of teacher education, 63(4), 237-244. 
[13] Administration for Children and Families. (1995). Passages to inclusion. Washington, DC: Administration for Children and Families Child Care Bureau (Available on WWW through http://ericps.crc.uiuc.edu/ncci/nccicome.html).

[14] D.B. Bailey, R.A. McWiUiam, V. Buysse, P. W. Wesley (1998). Inclusion in the context of competing values in early childhood education. Early Childhood Research Quarterly, 15(1).

[15] L. Ehrmann, S. Aeschleman, S. Svanum (1995). Parental reports of community activity patterns: A comparison between young children with disabilities and their nondisabled peers. Research in Developmental Disabilities, 16, 331-343.

[16] Mercer Jane, "I.Q.: The Lethal Label,” Psychology Today 6 (September 1972): 95-97, cited in James Trent, Inventing the Feeble Mind (Berkeley: University of California Press, 1994), 260.

[17] J. Fletcher, Spillover effects of inclusion of classmates with emotional problems on test scores in early elementary school. J. Policy Anal. Manag. 2010, 29, 69-83.

[18] E. Bould, C. Bigby, P.C. Bennett, T.J. Howell, 'More people talk to you when you have a dog' Dogs as catalysts for social inclusion of people with intellectual disabilities. J. Intellect. Disabil. Res. 2018, 62, 833-841.

[19] J. Mcleskey, N.L. Waldron . "Educational Programs for Elementary Students with Learning Disabilities: Can They Be Both Effective and Inclusive?" Learning Disabilities Research \& Practice 26.1(2011).

[20] R. Allington, A. McGill-Franzen (1989a). Different programs, indifferent instruction. In A. Gartner \& D. Lipsky (Eds.), Beyond separate education: Quality education for all (pp. 75-98). Baltimore: Brookes.

[21] R. Allington, A. McGill-Franzen (1989b). School response to reading failure: Chapter 1 and special education students in grades $2,4, \& 8$. Elementary School Journal, 89, 529-542.

[22] A. McGill-Franzen, D. Allington (1990). Comprehension and coherence: Neglected elements of literacy instruction in remedial and resource room services. Journal of Reading, Writing, and Learning Disabilities, 6, 149-180. (1989a, 1989b, 1991).

[23] A. McGill-Franzen, R. Allington (1991). The gridlock of low reading achievement: Perspectives on policy and practice. Remedial and Special Education, 12(3), 20-30.
[24] N. File (1994). Children's play, teacher-child interactions, and teacher beliefs in integrated early childhood programs. Early Childhood Research Quarterly, 9, 223-240.

[25] J. McLeskey, N. Waldron (2002a). Inclusion and school change: Teacher perceptions of curricular and instructional adaptations. Teacher Education and Special Education, 25, 41-54.

[26] W. Murawski (2006). Student outcomes in cotaught secondary English classes: How can we improve? Reading \& Writing Quarterly, 22, 227 247.

[27] W. Murawski, L. Swanson (2001). A meta-analysis of co-teaching research: Where are the data? Remedial and Special Education, 22, 258-267.

[28] N. Zigmond, J. Baker (1995). Concluding comments: Current and future practices in inclusive schooling. The Journal of Special Education, 29, 245-250.

[29] K. Bentum, P. Aaron (2003). Does reading instruction in learning disability resource rooms really work? A longitudinal study. Reading Psychology, 24, 361-382.

[30] S. Moody, S. Vaughn, M. Hughes, M. Fischer (2000). Reading instruction in the resource room: Set up for failure. Exceptional Children, 66, 305316.

[31] S. Russ, B. Chaing, B. Rylance, J. Bongers (2001). Caseload in special education: An integration of research findings. Exceptional Children, 67, 161172.

[32] R. Mittler, Working toward Inclusive Education: Social Contexts (London: DavidFulton Publishers, 2000) p. vii.

[33] K. Black (1996). A Healing Homiletic: Preaching and Disability (Nashville: Abingdon, 1996).

[34] S. Ripley (1997). Collaboration between General and Special Education Teachers. ERIC Digest.

[35] G. Laws, \& E. Kelly (2005). The attitudes and friendship intentions of children in United Kingdom mainstream schools toward peers with physical or intellectual disabilities. International Journal of Disability, Development \& Education, 52, 79-99.

[36] G.N. Siperstein, R.C. Parker, J.N. Bardon, \& K.F. Widaman (2007). A national study of youth attitudes toward the inclusion of students with intellectual disabilities. Exceptional Children, 73, 435-455. 
[37] E.A. Nowicki (2006). A cross-sectional multivariate analysis of children's attitudes toward disabilities. Journal of Intellectual Disability Research, 50, 335-348.

[38] A.A. De Boer, S.J. Pijl, W.J. Post, \& A.E.M.G Minnaert (2012). Which variables relate to the attitudes of teachers, parents and peers toward students with special educational needs in regular education? Educational Studies, 38, 433-448.

[39] House of Commons Education and Skills Committee. (2006). Special educational needs: Third report of session 2005-06. London, England: The Stationery Office Limited.

[40] E.S. Buhs, G.W. Ladd, \& S.L. Herald (2006). Peer exclusion and victimization: Processes that mediate the relation between peer group rejection and children's classroom engagement and achievement? Journal of Educational Psychology, 98, 1-13.

[41] S.M. Coyne, N. Gundersen, D.A. Nelson, \& L. Stockdale (2011). Adolescents' prosocial responses to ostracism: An experimental study. The Journal of Social Psychology, 151, 657-661.

[42] L. Stanley, \& T. Arora (1998). Social exclusion amongst adolescent girls: Their self-esteem and coping strategies. Educational Psychology in Practice, 14, 94-100.

[43] M. Verkuyten, \& J. Thijs (2006). Ethnic discrimination and global self-worth in early adolescents: The mediating role of ethnic selfesteem. International Journal of Behavioral Development, 30, 107-116.

[44] Van den Berg, Y. H. M., E. Segers, \& A.H.N. Cillessen (2012). Changing peer perceptions and victimization through classroom arrangements: A field experiment. Journal of Abnormal Child Psychology, 40, 403-412. http://dx.doi.org/10.1007/s10802-011-9567-6.

[45] S.Y. Stofile (2008). Factors affecting the implantation of inclusive education policy: A case study in one province in South Africa. Published Doctoral Thesis, University of Western Cape.

[46] L. Fuchs, D. Fuchs, N. Bishop (1992). Instructional adaptation for students at risk for academic failure. Journal of Educational Research, 86, 70-84.

[47] O, Burneau-Balderrama, 'Inclusion: Making It Work for Teachers, Too' in The Clearinghouse, 70:6 (1997).
[48] D.S. Huefner, The risks and opportunities of the IEP requirements under IDEA'97. J. Spec. Educ. 2000, 33, 195-204.

[49] C.L. Praisner, 'Attitudes of Eiementary School Principals toward the Inclusion of Students with Disabilities' in Exceptional Children, 69:2 (2003) pp. 135-145. 